\title{
PENGARUH PENERAPAN SISTEM INFORMASI DATABASE RISET DAN PENGABDIAN MASYARAKAT (SIDR) DI LINGKUNGAN UNIVERSITAS INDONESIA
}

\author{
Qurrotin A'yunina ${ }^{1}$, Muhamad Soleh ${ }^{2}$, Ari Wibisono ${ }^{3}$ \\ ${ }^{1,2,3}$ Fakultas Ilmu Komputer, Universitas Indonesia, Gedung A Fasilkom Lt. 2 No. 1231, Kampus Baru UI \\ Depok, Jawa Barat, 16424, Indonesia \\ E-mail: ari.w@cs.ui.ac.id
}

\begin{abstract}
Sistem Informasi Database Riset dan Pengmas (SIDR) is an information system that saves the reseach and community service data in Universitas Indonesia. To evaluate the effectiveness of SIDR, it is ideal to gather data about the SIDR user's responses. Consequently, in the present study, questionnaire method uses a 6-point Likert scale is applied to obtain that kind of information. In general, the results show that SIDR provides an effective means of creating and centralizing research and community service data for whole faculties in Universitas Indonesia.
\end{abstract}

Keywords: SIDR, information system, responses

\begin{abstract}
Abstrak
Sistem Informasi Database Riset dan Pengabdian Masyarakat (SIDR) merupakan suatu sistem informasi yang digunakan untuk menyimpan data riset dan pengabdian mayarakat di lingkungan Universitas Indonesia. Untuk mengevaluasi keefektifan SIDR, perlu dilakukan pengambilan data tentang respon pengguna SIDR terhadap teknologi sistem informasi ini. Sehingga dalam studi ini, metode kuisioner dengan 6 poin skala Likert diterapkan untuk mendapatkan informasi tersebut. Secara umum, hasil penelitian menunjukkan bahwa SIDR memberikan kemudahan dalam pembuatan laporan hasil riset serta terpusatnya data-data hasil riset dan pengabdian masyarakat untuk seluruh fakultas di Universitas Indonesia.
\end{abstract}

Kata Kunci: SIDR, sistem informasi, respon

\section{Pendahuluan}

Tiga prinsip dasar yang harus dijunjung oleh seluruh sivitas akademika di dalam perguruan tinggi yang ada di Indonesia adalah Tri Dharma Perguruan Tinggi. Poin-poin dari Tri Dharma Perguruan Tinggi, yaitu pendidikan, penelitian dan pengembangan, serta pengabdian masyarakat. Dosen merupakan salah satu dari sivitas akademika yang memegang peranan penting dalam memajukan kualitas suatu perguruan tinggi. Selain mengajar, setiap dosen diwajibkan untuk meneliti guna mengaplikasikan serta mengembangkan ilmu pengetahuan yang dimiliki.

Penelitian ini menjadi sangat berarti apabila hasilnya dapat dipublikasikan dalam suatu jurnal maupun konferensi nasional/internasional. Selain dapat dipublikasikan, hasil penelitian ini juga dapat diterapkan dalam masyarakat yang nantinya dapat membantu menyelesaikan permasalahan yang ada dalam komunitas tersebut. Data mengenai hasil-hasil penelitian yang telah terpublikasi maupun yang dimanfaatkan sebagai sarana pengabdian masyarakat ini perlu dikelola dengan baik dan transparan. Hal ini perlu dilakukan agar data-data hasil publikasi dan pengabdian masyarakat dapat tersimpan dengan aman. Selain itu, dapat menjadi bukti dalam penilaian mutu penelitian setiap perguruan tinggi.

Universitas Indonesia yang merupakan salah satu perguruan tinggi papan atas di Indonesia telah menerapkan suatu sistem sistem informasi yang dapat mempermudah dalam hal pengumpulan data riset dan pengabdian masyarakat. Sistem ini dinamakan dengan SIDR (Sistem Informasi Database Riset dan Pengmas). Sebelum SIDR ini diterapkan, Universitas Indonesia menggunakan penyimpanan secara manual dengan menggunakan bantuan Microsoft Excel. Metode penyimpanan ini sangat beresiko terhadap kehilangan data sehingga mengakibatkan pengelolaan data riset menjadi tidak baik.

SIDR dikembangkan dengan menggunakan (Content Management System) CMS Drupal 7. Drupal merupakan suatu open source perangkat lunak yang didistribusikan oleh General Public License (GPL). Drupal dapat diunduh secara bebas dan memungkinkan pengunduhnya untuk 
mengatur, mengelola serta mempublikasi suatu konten dalam website. Drupal tidak terpengaruh khusus pada sistem operasi seperti Linux, Microsoft Windows, Mac OS X, FreeBSD, Solaris dan lain-lain selama sistem operasi tersebut dapat menjalankan PHP [1].

Sesuai dengan namanya, Sistem Informasi Database Riset dan Pengmas (SIDR) dapat menyediakan laporan data penelitian dan pengmas setiap dosen di Universitas Indonesia serta statistik performance dari hasil riset sesuai dengan permintaan pengguna dan kategori laporan. Sistem ini dapat membagi fungsionalitas pelaporan dan penyimpanan sesuai dengan role user. Beberapa data penelitian yang dapat diolah dalam SIDR, antara lain:

1) Kegiatan Forum Ilmiah

Kegiatan Forum Ilmiah merupakan menu untuk melihat daftar penyelenggaraan kegiatan forum ilmiah yang dilaksanakan oleh perguruan tinggi dalam bentuk seminar, lokakarya, konferensi, dan ekspose hasil-hasil penelitian, dalam tingkat internasional, nasional, atau regional.

\section{2) Luaran Penelitian:}

\section{a) Buku Teks/Ajar}

Buku teks/ajar merupakan karya ilmiah yang dibuat oleh peneliti di Universitas Indonesia yang diterbitkan oleh penerbit yang ditunjuk. Buku tersebut telah melalui proses editing dan sudah dicetak.

b) Pemakalah Forum Ilmiah

Pemakalah Forum Ilmiah adalah seorang peneliti di Universitas Indonesia yang mempublikasikan artikel ilmiah dengan cara mengikuti suatu konferensi nasional maupun internasional.

c) Publikasi Ilmiah/Jurnal

Jurnal Ilmiah adalah artikel publikasi ilmiah yang dipublikasikan oleh peneliti di universitas Indonesia melalui beberapa pengelola jurnal, baik jurnal nasional maupun internasional.

d) Hak Kekayaan Intelektual

Hak Kekayaan Intelektual merupakan menu yang menampilkan data hak kekayaan intelektual, jika pengguna merupakan pengguna dari suatu fakultas maka data hak kekayaan intelektual yang ditampilkan adalah data hak kekayaan intelektual dari fakultas tersebut.

e) Luaran Lain

Luaran lain merupakan menu yang menampilkan data luaran lain, jika pengguna merupakan pengguna dari suatu fakultas maka data luaran lain yang ditampilkan adalah data luaran lain dari fakultas tersebut.

\section{3) Revenue Generating}

Menu revenue generating merupakan menu yang meliputi data kegiatan non penelitian yang menghasilkan dana, meliputi sub menu:

a) Hibah Non Penelitian/ Kontrak Kerja Hibah Non Penelitian/ Kontrak Kerja merupakan menu yang menampilkan data hibah non penelitian/kontrak kerja, jika pengguna merupakan pengguna dari suatu fakultas maka data hibah non penelitian/kontrak kerja yang ditampilkan adalah data hibah non penelitian/kontrak kerja dari fakultas tersebut.

b) Unit Bisnis Hasil Riset

Unit Bisnis Hasil Riset merupakan menu yang menampilkan data unit bisnis hasil riset, jika pengguna merupakan pengguna dari suatu fakultas maka data unit bisnis hasil riset yang ditampilkan adalah data unit bisnis hasil riset dari fakultas tersebut.

\section{4) Program Pengmas}

Menu Program Pengmas merupakan menu yang digunakan untuk melihat daftar pengabdian masyarakat.

\section{5) Verifikasi Data}

Menu Verifikasi Data merupakan menu yang digunakan untuk melihat data riset dan pengabdian masyarakat yang belum diverifikasi kebenaran datanya. Menu ini digunakan oleh pengguna yang memiliki role Staf Manajer (Verifikator) dan Manajer Riset dari setiap fakultas.

\section{6) Data Riset dan Pengmas}

Untuk mengetahui perbandingan antara sebelum dan sesudah penggunaan SIDR, maka perlu dilakukan evaluasi penggunaan SIDR. Usability Evaluation Method (UEM) merupakan suatu metode yang terdiri dari serangkaian kegiatan pengumpulan data yang berhubungan dengan interaksi end-user dengan produk perangkat lunak dan atau bagaimana sifat-sifat khusus dari perangkat lunak ini berkontribusi untuk mencapai tingkat kegunaan tertentu. Secara umum, UEM dibagi menjadi dua metode, metode empiris dan metode inspeksi. Metode empiris yaitu metode yang berdasarkan pada pengambilan data beserta analisisnya. Sedangkan, metode inspeksi dilakukan oleh evaluator yang ahli di bidangnya [2].

Dua metode ini memiliki kelebihan dan kekurangan. Kelebihan dari metode empiris adalah hasil evaluasinya dapat mencakup sebagian maupun seluruh end-user produk perangkat lunak tertentu. Akan tetapi, pengambilan data ini memakan banyak biaya, 
mengingat banyaknya responden yang ikut dalam evaluasi ini. Sedangkan, kelebihan dari metode inspeksi adalah membutuhkan lebih sedikit sumber data, sehingga pengolahan serta analisisnya sederhana. Namun, penilaiannya hanya terbatas oleh dugaan evaluatornya saja. Selain itu, interaksi antara end-user dengan perangkat lunak tidak dipertimbangkan dalam hasil pengamatan evaluator [2].

Kuisioner merupakan salah satu bagian dari metode empiris. Data yang didapatkan dari kuisioner dapat berupa data kuantitatif dan data kualitatif. Data kuantitatif merupakan data yang berbentuk angka. Data ini diperoleh dari kuisioner dengan jawaban berskala. Sedangkan, data kualitatif merupakan data yang berbentuk kalimat.

Penggunaan kuisioner telah banyak diterapkan dalam mengevaluasi produk perangkat lunak. Cao et al. [3] mengevaluasi Agent99 trainer, sebuah sistem pelatihan multimedia berbasis web yang berisi pelatihan deteksi penipuan. Evaluasi ini dilakukan untuk menguji kegunaan, kemudahan, efektifitas dan kepuasan pengguna terhadap Agent99 trainer. Untuk mendukung penelitiannya, data kualitatif dan kuantitatif dikumpulkan dengan menggunakan kuisioner. Untuk menganalisis hasil kuisioner, Cao et al. [3] membandingkan nilai mean masingmasing pertanyaan, Hasil evaluasi menunjukkan bahwa Agent99 trainer merupakan sistem yang memiliki kegunaan yang baik, sistem dapat dengan mudah dipelajari dan digunakan.

Metode kuisioner juga digunakan Zaharias [4] untuk mengevaluasi aplikasi e-learning yang difokuskan pada motivasi belajar. Kuisioner terdiri dari 64 butir pertanyaan, 54 soal bertujuan untuk mengukur kegunaan web dan desain instruksional dan 10 soal untuk mengukur motivasi belajar. Jawaban kuisioner berskala Likert dengan poin 1-5. Hasil penelitian menunjukkan bahwa semua faktor memiliki nilai konsistensi yang tinggi. Selain itu, Variabel motivasi belajar merupakan variabel dengan nilai konsistensi yang sangat tinggi.

Pada penelitian ini, untuk mengevaluasi penerapan SIDR di lingkungan Universitas Indonesia, prosedur yang dilakukan adalah dengan menggunakan metode kuisioner berskala Likert.

\section{Metodologi}

Metode yang diterapkan dalam penelitian adalah metode penelitian survei dengan menggunakan kuisioner. Alur proses penelitian yang dilakukan dapat dilihat pada Gambar 1.
Tahap pertama adalah penyusunan konten kuisioner. Kuisioner berisi 12 pertanyaan, dengan rincian: 10 pertanyaan dengan jawaban berskala $1-6(1=$ sangat tidak setuju, $6=$ sangat setuju $)$, satu pertanyaan dengan jawaban optional dan sisanya, pertanyaan berupa masukan, saran dan kritik. Daftar pertanyaan dapat dilihat pada Appendix.

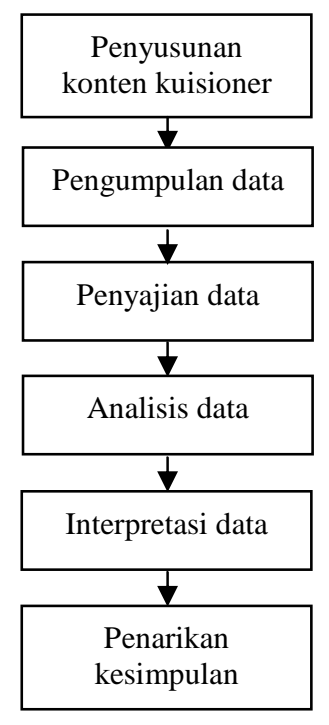

Gambar 1. Alur proses penelitian

Pertanyaan tersebut dibagi menjadi dua kategori, kategori pertama digunakan untuk mengetahui tingkat keberhasilan penerapan SIDR, dengan mengacu pada tujuan pengembangan SIDR, diantaranya:

1) Membangun sistem yang mampu memberikan kemudahan dalam pengumpulan data riset bagi setiap fakultas di Universitas Indonesia.

2) Membangun sistem yang mampu memberikan kemudahan dalam pembuatan laporan hasil riset di Universitas Indonesia berdasarkan kategori pelaporan yang dibutuhkan.

3) Membangun sistem yang mampu memberikan statistik data riset dan performance dosen untuk setiap fakultas di Universitas Indonesia.

4) Terpusatnya data-data hasil riset dan pengabdian masyarakat di Universitas Indonesia.

5) Terintegrasinya seluruh data penelitian dengan data kepegawaian di Universitas Indonesia.

Sedangkan kategori kedua digunakan untuk mengetahui tingkat kepuasan pengguna tentang kelayakan layanan SIDR seperti penggunaan menu navigasi, menu $\log$ in, pengisian data. 


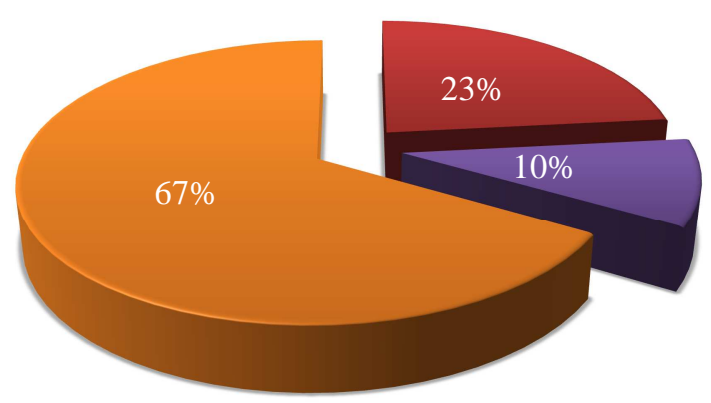

$\square$ Manajer riset $\square$ Staff administrator DRPM $\square$ Staff data entry

Gambar 2. Persentase Jumlah Responden

Kuisioner dibuat dengan memanfaatkan fasilitas form pada Google Docs. Dengan menggunakan fasilitas ini, kuisioner dapat dibagikan secara online kepada para responden. Kuisioner ini diisi oleh manajer riset fakultas di Universitas Indonesia, staff data entry, dan staff administrator DRPM (Direktorat Riset dan Pengabdian Masyarakat). Penggunaan Google Docs sangat membantu dalam proses pengolahan data, karena hasil survei langsung dapat diakses dan disajikan. Setelah proses penyajian data dilakukan, maka data akan lebih mudah untuk dianalisis dan diinterpretasikan.

Total jumlah responden adalah sebanyak 30 orang. Gambar 2 menunjukkan persentase jumlah responden. Staff data entry merupakan responden terbanyak, diikuti oleh manajer riset, kemudian staff administrator DRPM. Survei ini dilakukan sejak tanggal 11-24 Maret 2015.

\section{Hasil dan Analisis}

Sebelum dilakukan analisis, data kuantitatif yang diperoleh dari hasil kuisioner perlu diuji validitasnya untuk mengukur valid tidaknya tiaptiap butir kuisioner. Rumus uji validitas adalah sebagai berikut:

$$
r_{x y}=\frac{N \Sigma X Y-\Sigma X \Sigma Y}{\sqrt{N \Sigma X^{2}-(\Sigma X)^{2}} \sqrt{N \Sigma Y-(\Sigma Y)^{2}}}
$$

$$
\begin{aligned}
& \text { Keterangan: } \\
& r_{x y} \quad=\text { koefisien korelasi }\left(\mathrm{r}_{\text {hitung }}\right) \\
& X \quad=\text { skor item } \\
& Y \quad=\text { skor total } \\
& N \quad=\text { banyaknya subyek }
\end{aligned}
$$

\begin{tabular}{|c|c|c|c|c|c|c|c|c|c|c|}
\hline \multirow{2}{*}{ Skala } & \multicolumn{10}{|c|}{ Pernyataan No. } \\
\hline & 1 & 2 & 3 & 4 & 5 & 6 & 7 & 8 & 9 & 10 \\
\hline 1 & 0 & 0 & 1 & 0 & 1 & 0 & 2 & 1 & 0 & 0 \\
\hline 3 & 3 & 1 & 1 & 1 & 5 & 3 & 4 & 6 & 4 & 4 \\
\hline 4 & 3 & 2 & 1 & 6 & 7 & 13 & 12 & 8 & 13 & 4 \\
\hline 5 & 6 & 9 & 9 & 13 & 5 & 7 & 7 & 7 & 8 & 9 \\
\hline Nilai & & & & & & & & & & \\
\hline $\begin{array}{r}\text { Korelasi } \\
\left(\mathrm{r}_{\text {hitung }}\right)\end{array}$ & 0.64 & 0.71 & 0.76 & 0.58 & 0.68 & 0.73 & 0.36 & 0.64 & 0.81 & 0.82 \\
\hline Mean & 5.3 & 5.47 & 5.37 & 5.07 & 4.43 & 4.47 & 4.1 & 4.33 & 4.47 & 4.9 \\
\hline
\end{tabular}

\begin{tabular}{|c|c|c|c|c|c|c|c|c|c|c|}
\hline \multicolumn{11}{|c|}{ Pernyataan No. } \\
\hline & 1 & 2 & 3 & 4 & 5 & 6 & 7 & 8 & 9 & 10 \\
\hline Tidak Setuju (\%) & 10 & 3 & 7 & 3 & 27 & 13 & 23 & 27 & 13 & 17 \\
\hline Setuju (\%) & 90 & 97 & 93 & 97 & 73 & 87 & 77 & 73 & 87 & 83 \\
\hline
\end{tabular}

TABEL I

HASIL KUISIONER

TABEL II

Hasil PENGElompokKan DuA Kutub (SETUJu DAN TIDAK SETUJu)

Uji ini dapat disederhanakan dengan menggunakan formula (=correl (array1, array2)) dalam microsoft excel. Tahapan awalnya adalah dengan menjumlahkan jawaban para responden. Array1 merupakan hasil blok pertanyaan, sedangkan array 2 adalah hasil blok total jumlah jawaban.

Hasil formula tersebut dibandingkan dengan nilai $\mathrm{r}$ pada tabel tingkat signifikansi uji dua arah.
Tingkat signifikansi $(\alpha)$ dipilih sebesar 0.05 dengan df sebesar 28, sehingga didapatkan nilai $\mathrm{r}_{\text {tabel }}$ sebesar 0.3610. Setelah dibandingkan, ternyata nilai korelasi dari seluruh pertanyaan lebih besar dari nilai $r_{\text {tabel }}$. Sehingga, hasil survei dapat dikatakan valid dan dapat dianalisis. Perbandingan ini dapat dilihat pada TABEL I. TABEL I juga memberikan informasi mengenai nilai mean atau rata-rata dari setiap pernyataan. 
Pada tabel tersebut, terdapat 4 pernyataan yang memiliki nilai mean lebih besar dari 5, yaitu pernyataan no. 1-4 yang berkaitan dengan manfaat penerapan SIDR. Hal ini menunjukkan para responden merasa sangat setuju dengan pernyataan pada poin-poin ini.

TABEL I dapat dianalisis lebih lanjut dengan memisahkan skala tingkat pilihan sesuai dengan kutubnya, sehingga dapat dihasilkan dua kutub berbeda, yaitu:

1) Tidak setuju

Kelompok "tidak setuju" merepresentasikan tiga pilihan, yaitu sangat tidak setuju (1), tidak setuju (2), dan cukup tidak setuju (3).

2) Setuju

Kelompok "setuju" ini menggabungkan tiga pilihan, yaitu sangat setuju (4), setuju (5) dan cukup setuju (6).

Hasil pemisahan ini dapat dilihat pada TABEL II. Berdasarkan hasil pengamatan yang dilakukan pada tabel tersebut, masing-masing kelompok memiliki persentase yang berbeda. Persentase kelompok "setuju" lebih besar dari "tidak setuju". Selain itu, persentase tertinggi pada TABEL II yaitu sebesar $97 \%$. Persentase ini berkaitan dengan pernyataan $2 \& 4$, yaitu SIDR dapat membangun sistem yang memberikan kemudahan dalam pembuatan laporan hasil riset serta membatu terpusatnya data-data hasil riset dan pengabdian masyarakat di Universitas Indonesia. Sehingga bisa dikatakan bahwa para responden sangat merasakan manfaat SIDR yang ada pada dua poin ini.

Sebaliknya, persentase terendah yaitu sebesar $73 \%$. Persentase ini berhubungan dengan pernyataan $5 \& 8$, yaitu terintegrasinya seluruh data penelitian dengan data kepegawaian di Universitas Indonesia, serta kemudahan dalam mengisi SIDR. Hal ini dikarenakan pada penggunaaan SIDR, data penelitian tidak terintegrasi dengan data kepegawaian dan kemahasiswaan, seperti SIPEG dan SIAK. Selain itu, ada beberapa responden merasa tidak bisa mengakses SIDR dengan lancar, dikarenakan kecepatan jaringan yang lambat.

TABEL III

PERSENTASE MASING-MASING KATEGORI

\begin{tabular}{lcc}
\hline & $\begin{array}{c}\text { Kategori I (Tingkat } \\
\text { Keberhasilan } \\
\text { Penerapan SIDR) }\end{array}$ & $\begin{array}{c}\text { Kategori II } \\
\text { (Tingkat } \\
\text { Pelayanan } \\
\text { SIDR) }\end{array}$ \\
\hline $\begin{array}{l}\text { Rata-rata persentase } \\
\text { pemilihan(\%) }\end{array}$ & 90 & 81 \\
\hline
\end{tabular}

Apabila ditinjau dari dua kategori pernyataan pada kuisioner, yaitu tingkat keberhasilan penerapan SIDR (pernyataan no. 1-5) dan tingkat pelayanan SIDR (pernyataan no. 6-10), maka kategori pertama memiliki rata-rata persentase yang lebih besar dibandingkan dengan kategori kedua. Kedua kategori dapat dilihat pada TABEL III. Kategori pertama sebesar $90 \%$, dan kategori kedua hanya $81 \%$. Hal ini menunjukkan bahwa SIDR sangat berhasil diterapkan di Universitas Indonesia. Keberhasilan ini dicapai karena SIDR telah memberikan pengaruh positif terhadap manajemen data hasil penelitian, meliputi proses pengumpulan, pengelolaan serta pelaporan data hasil penelitian di lingkungan Universitas Indonesia. Dengan kata lain,.para pengguna SIDR sangat merasakan manfaat SIDR, namun, perlu ditunjang dengan adanya peningkatan pelayanan.

Sedangkan, pada pertanyaan dengan jenis jawaban optional (pertanyaan no. 11), diperoleh hasil yang cukup mengejutkan. Dari 30 responden, terdapat tiga responden yang tetap memilih menggunakan metode manual, yaitu dengan menggunakan Microsoft Excel. Penyebab keengganan mereka menggunakan SIDR karena sistem pengaksesan SIDR yang cukup lama, proses pemasukan data yang tidak efisien serta kurang adanya pemahaman terhadap fasilitas export data dari SIDR ke Microsoft Excel, sehingga diantara mereka ada yang merasa kesulitan untuk mendapatkan data hasil penelitian per fakultas.

Permasalahan yang dirasakan oleh beberapa pengguna dapat diminimalisir dengan melakukan beberapa saran dan masukan yang diberikan oleh para responden. Saran dan masukan ini juga berguna untuk meningkatkan pelayanan SIDR. Beberapa saran dan masukan dari para responden diantaranya:

1) Kualitas jaringan SIDR perlu ditingkatkan.

2) Terintegrasinya data dari SIPEG (Sistem Informasi Kepegawaian), SIAK-NG (Sistem Informasi Akademik-Next Generation), atau sistem informasi lain yang ada di Universitas Indonesia agar dapat terhubung secara otomatis ke SIDR.

3) Menu/ navigasi lebih disederhanakan lagi.

4) Perlu adanya pelatihan kepada staf-staf di fakultas.

5) Sistem monitoring dilakukan dalam 3 bulanan atau semesteran agar data selalu update.

6) Penerapan export data SIDR diharapkan sama seperti SIAK-NG agar mudah dalam pencetakan data. 


\section{Kesimpulan dan Saran}

Penerapan SIDR di lingkungan Universitas Indonesia sangat dirasakan manfaatnya oleh para pengguna SIDR, yaitu manajer riset, staff data entry dan staff administrator DRPM. Manfaat yang paling dominan yaitu berkaitan dengan kemudahan dalam pembuatan laporan hasil riset serta terpusatnya data-data hasil riset dan pengabdian masyarakat di lingkungan Universitas Indonesia.

Akan tetapi, terdapat dua hal penting yang perlu mendapat perhatian lebih dari tim pengembang SIDR yaitu agar dalam pengembangan SIDR selanjutnya data yang berkaitan dengan data penelitian dan pengabdian masyarakat dapat terintegrasi serta kecepatan akses SIDR dapat ditingkatkan.

\section{Referensi}

[1] https://www.drupal.org/about, retrieved February 25, 2015

[2] A. Fernandez, E. Insfran, S. Abrahao, "Usability Evaluation methods for the web: A Systematic Mapping Study", Information and Software Technology, vol. 53, pp. 789817, 2011.

[3] J. Cao, J.M. Crews, J.F. Nunamaker, J.r., J.K. Burgoon, M. Lin, "User Experience With Agent 99 Trainer: A Usability Study", In Proceeding of 37th Hawaii International Conference on System Sciences, pp. 1-11, 2004.

[4] P. Zaharias, "A Usability Evaluation Method for e-learning: Focus on Motivation to Learn", CHI, pp.1571-1576, 2006.

\section{Lampiran}

LAMPIRAN TABEL I

DAFTAR PERTANYAAN

1 SIDR mempermudah dalam hal pengumpulan data riset dan pengabdian masyarakat dari seluruh fakultas

1233456

2 SIDR memberikan statistik data riset dan performance untuk setiap fakultas di Universitas Indonesia

1223456

3 SIDR membantu terpusatnya data-data hasil riset dan pengabdian masyarakat di Universitas Indonesia

1233456

4 SIDR memberikan pelaporan hasil riset dan pengmas di Universitas Indonesia berdasarkan kategori pelaporan yang dibutuhkan

1223456

5 SIDR dapat mengintegrasikan seluruh data penelitian dengan data kepegawaian di Universitas Indonesia

12334556

$6 \quad$ Menu navigasi dalam SIDR jelas

1223456

7 Saya dapat masuk (log in) SIDR dengan mudah

1223456

8 Saya dapat mengisi data dalam SIDR dengan mudah

1233456

$9 \quad$ Saya puas menggunakan SIDR

12234556

10 Tanpa SIDR, data penelitian dan pengmas tidak terstruktur dengan baik dan transparan

1233456

11 Metode apa yang anda suka dalam memasukkan data-data riset dan pengmas

a. Manual

b. SIDR

c. Metode lainnya

12 Ide, saran, dan kritik untuk pengembangan Sistem Database Riset dan Pengmas (SIDR) ke depannya 